\title{
Simplification and standardization of serodiagnostic tests for leprosy based on phenolic glycolipid-I (PG-I) antigen
}

\author{
G AGUADO SANCHEZ, A MALIK, C TOUGNE, PH LAMBERT \& \\ HD ENGERS \\ WHO Immunology Research and Training Center, Dept. Pathology, \\ University of Geneva Medical School, Geneva, Switzerland
}

\section{Introduction}

Epidemiological studies suggest that one of the main objectives in leprosy control would be prevention of the spread of bacilli from multibacillary and subclinical subjects to contacts. Therefore reliable immunodiagnostic tests for the early detection of $M$. leprae-specific antibodies and/or antigens are urgently needed. Such tests should be specific, simple, rapid, economical and relatively easy to carry out in endemic areas.

One of the first $M$. leprae-specific antigens to be isolated and characterized was phenolic glycolipid-I (PG-I), a major glycolipid present in the serologically active lipid preparation derived from $M$. leprae (Fig. 1, ref. 1-3). The principal antigenic determinant of PG-I was shown to consist of an unique trisaccharide moiety (1). Soon after its discovery, PG-I was employed in the native form as a substrate in enzyme-linked immunosorbent assays (ELISA) for the detection of PG-I-specific antibody responses in leprosy patients (4-6). However, since the PG-I molecule is quite apolar, sonication (4), detergent treatment (5) or deacylation (6) was required to solubilize the antigen molecule prior to coating the ELISA plates. Subsequently, an elegant study by Young et al. (7) confirmed that the primary site for antibody binding was the non-reducing 3,6-di-O-Methyl- $\beta$-O-Glucopyranose terminus of the PG-I molecule. Five out of 9 monoclonal antibodies (Mabs) produced against PG-I recognized specifically the distal sugar epitope, and removal of the single terminal sugar was sufficient to abrogate antibody binding to the PG-I molecule. These and other results suggested that the chemical synthesis of the disaccharide moiety could perhaps provide a specific tool for the serodiagnosis of leprosy. Indeed, such a synthetic antigen has been synthesized independently by two groups (8-11) and the serologically active disaccharide conjugated to bovine serum albumin (D-BSA) as a protein carrier for use in ELISA. The availability of this pure, defined synthetic antigen in gram amounts should now permit detailed, standardized studies to be carried out in leprosy endemic areas throughout the world.

The detection of PG-I antigen in the saliva, serum or urine of multibacillary patients has been reported recently, using a radiolabelled Mab as a probe $(12,13)$. However, the method as described is not suitable for use in endemic areas. Since the levels of circulating PG-I antigen have been reproted to drop below detection 8-12 weeks following initiation of chemotherapy (13), an appropriate PG-I detection assay may allow one to monitor the success of multidrug therapy, as well as to identify those patients undergoing a relapse $(13,14)$. 
In this report we present data from our laboratory related to : (i) the standardization of the microplate ELISA for the detection of anti-PG-I IgM antibodies using the D-BSA synthetic antigen ; (ii) the simplification of sample collection techniques : (iii) the development and evaluation of a modification of the rapid, sensitive, visual «dot ELISA» (15) using the synthetic D-BSA antigen and nitrocellulose filters as the solid phase ; and (iv) preliminary results concerning the detection of PG-I antigen in the urine of leprosy patients using a rapid, simple, non-isotopic «dot ELISA» detection technique.

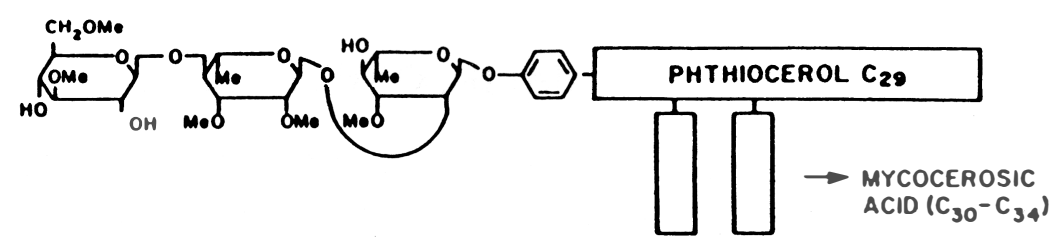

Figure 1. Chemical structure of the M. leprae-specific phenolic glycolipid 1 .

\section{Material and methods}

\section{ANTIGENS}

Purified PG-I and D-BSA synthetic antigen were kindly provided by Dr P. Brennan, Fort Collins, CO through NIAID contract No 1 AI-52582. D-BSA antigen was also supplied by Dr R. Gigg, Mill Hill, London, England, under a contract to the Immunology of Leprosy (IMMLEP) program, W.H.O., Geneva.

\section{MICROPLATE ELISA}

This assay was carried out following the methodology described by Cho. et al. (9). Briefly, the synthetic antigen, D-BSA $(50 \mu \mathrm{g} / \mathrm{ml}$ in carbonate-bicarbonate buffer $\mathrm{pH} 9.6)$ was used to coat round bottom ELISA plates (NUNC, Gibco AG, Basel, Switzerland) at a concentration of $0.2 \mu \mathrm{g} / \mathrm{ml}$, overnight at $37^{\circ} \mathrm{C}$. Plates were then washed with phosphate-buffered saline solution containing $1 \% \mathrm{v} / \mathrm{v}$ tween 20 (PBST) and blocked with $150 \mu \mathrm{l}$ PBST containing $1 \%$ bovine serum albumin, (BSA) (fraction (V), SIGMA, Chemical, Co., St. Louis, Mo.) for $1 \mathrm{~h}$ at $37^{\circ} \mathrm{C}$. A dilution of the serum to be tested $(1: 300$ in PBST containing $10 \%(\mathrm{v} / \mathrm{v})$ normal goat serum, (NGS, GIBCO, A.G.) was added to the plates $(50 \mu \mathrm{l})$ and incubated at $37^{\circ} \mathrm{C}$ for $1 \mathrm{~h}$. After washing, the plates were incubated for $1 \mathrm{~h}$ at $37^{\circ} \mathrm{C}$ with peroxidase-conjugated anti-human IgM reagent (CAPPEL, COOPER Biomedical Inc. Malvern PA) diluted 1:1000 in PBST-10\% NGS. The substrate used was 0-phenylene diamine (OPD) in citrate-phosphate buffer ( $\mathrm{pH} 5.0$ ) together with $0.01 \% \mathrm{H}_{2} \mathrm{O}_{2}$ and the resulting absorbances were read at $492 \mathrm{~nm}$ in an automated ELISA reader (TITERTEK Multiskan; Flow Laboratories, A.G.).

\section{DOT ELISA FOR ANTIBODY DETECTION}

A plexiglass incubation chamber which allows one to incubate 96 sera at once on a nitrocellulose membrane was used for the «dot ELISA» test. The nitrocellulose membrane $(0.45 \mu \mathrm{m}$ pore size, SCHLEICHER \& SCHUELL) was cut to the dimensions of the chamber, rinsed with distilled water for $10 \mathrm{~min}$ and dried for $30 \mathrm{~min}$ at $37^{\circ} \mathrm{C}$. Using a template, $50 \mathrm{ng}$ of D-BSA antigen in $1 \mu \mathrm{l}$ Tris Buffered Saline (TBS, 50mM Tris, $200 \mathrm{mM} \mathrm{NaCl}, \mathrm{pH} 7.4$ ) were applied to the nitrocellulose membrane with a Hamilton syringe. The membrane was dried at R.T. for $30 \mathrm{~min}$ and blocked by incubation with TBS containing $3 \% \mathrm{BSA}$ at $37^{\circ} \mathrm{C}$ for $30 \mathrm{~min}$. 
The membrane was placed into the chamber and the serum dilutions (1:300) in TBS containing $1 \%$ BSA were added in duplicate $(200 \mu \mathrm{l} /$ well $)$ and incubated for $30 \mathrm{~min}$ at $37^{\circ} \mathrm{C}$. Three-fold dilutions of the positive control serum were done for each filter sheet tested. The nitrocellulose paper was removed from the chamber, placed into a large petri dish, washed three times 5 min each in TBS pH 7.4 with $0.02 \%$ tween 20. Peroxidase-conjugated anti-human IgM reagent (1:1000) (CAPPEL), diluted in TBS $1 \%$ BSA, was added and incubated for $30 \mathrm{~min}$ at $37^{\circ} \mathrm{C}$. The membrane was washed and the test was revealed by adding 4-Chloro-1-Napthol, $3 \mathrm{mg} / \mathrm{ml}$ (MERCK) in anhydrous methanol diluted 1:6 in TBS; Hydrogen peroxide (MERCK) was added to a final concentration of $0.03 \%$. This peroxidasesubstrate solution was prepared fresh before each use. The reaction was carried out for 30 min at $37^{\circ} \mathrm{C}$ (agitating each $10 \mathrm{~min}$ ) after which the nitrocellulose membrane was rinsed with distilled water, dried and stored in the dark.

\section{DOT ELISA FOR PG-I ANTIGEN DETECTION IN URINE}

The extraction of lipids from urine samples was carried out essentially following the method of Bligh-Dyer (16). After evaporation of the chloroform, the lipid extract was dissolved in 2 $\mathrm{ml}$ hexane and further concentrated to $20 \mu \mathrm{l}$ in hexane. The "dot ELISA» was performed according the method described by Kumar et al. (17), but using a polysulfone filter membrane as the solid support (13) as described by Young et al. Briefly, polysulfone strips were soaked in distilled water and dried. One microliter of the extracted urine lipids (in hexane) was spotted on the membrane using a template. Then the non-specific sites were blocked by incubation of the filter paper strip in TBS-3\% BSA for $1 \mathrm{~h}$ at $37^{\circ} \mathrm{C}$. The filter papers were washed 3 x $5 \mathrm{~min}$ in TBS and then incubated for $1 \mathrm{~h}$ at $37^{\circ} \mathrm{C}$ in a $1: 100$ dilution of a standard LL patient's serum diluted in TBS-1 \% BSA. This serum had been selected for use based on its high content of anti-PG-I antibodies.

The filter paper strips were again washed $3 \times 5 \mathrm{~min}$ in TBS and incubated $1 \mathrm{~h} 37^{\circ} \mathrm{C}$ with the same goat anti-human IgM-horseradish peroxidase conjugate (Cappel) as used for the microplate ELISA (1:1000 dilution). After washing, the presence of PG-I antigen was revealed by incubation for $15 \mathrm{~min}$ in the substrate solution consisting of 4 chloro- l-napthol ( $3 \mathrm{mg} / \mathrm{ml}$ in methanol) diluted 6 fold in TBS plus $0.03 \% \mathrm{H}_{2} \mathrm{O}_{2}$. Finally, the filters were washed in TBS, dried and stored in the dark.

\section{CLINICAL SAMPLES}

Serum and urine samples were collected from healthy normal individuals (Switzerland and India), culture positive tuberculosis patients (Switzerland, Spain and Algeria) and leprosy patients (Switzerland, China, India, Ethiopia and Brazil) and stored frozen until tested. The samples of body fluids from leprosy patients originated from treated and untreated patients, unless otherwise noted.

\section{Results}

\section{COMPARISON OF TWO INDEPENDENT SOURCES}

\section{OF D-BSA SYNTHETIC ANTIGEN FOR ELISA}

When D-BSA synthetic antigens synthesized in 2 independent laboratories (Dr J.P. Brennan and Dr R. Gigg) were tested as substrates in microplate ELISA for the detection of human anti-PG-I IgM antibodies, virtually identical results were obtained (Tables 1 and 2). With regards to the source of serum samples, the results were essentially as expected, control and culture positive tuberculosis sera were negative and sera from multibacillary leprosy patients generally positive unless they had undergone treatment for more than 2-3 years. 
Table 1. Comparison of two independent sources of D-BSA synthetic antigen as ELISA substrate for the detection of anti-PG-1 antibodies

\begin{tabular}{|c|c|c|c|c|}
\hline Serum & Diln & BSA & $\begin{array}{l}\text { D-BSA } \\
\text { Brennan }\end{array}$ & $\begin{array}{c}\text { D-BSA } \\
\text { Gigg }\end{array}$ \\
\hline \multicolumn{5}{|c|}{ LL patients (India)* } \\
\hline 1 & $1: 300$ & 0.02 & 0.05 & 0.11 \\
\hline 3 & & 0.0 & 0.0 & 0.04 \\
\hline 4 & & 0.06 & 0.19 & 0.20 \\
\hline 5 & & 0.01 & 0.05 & 0.04 \\
\hline 6 & & 0.09 & 0.70 & 0.72 \\
\hline 7 & & 0.23 & 0.32 & 0.41 \\
\hline 8 & & 0.20 & 1.38 & 1.45 \\
\hline 9 & & 0.51 & 0.99 & 0.87 \\
\hline 10 & & 0.07 & 0.81 & 0.99 \\
\hline \multicolumn{5}{|c|}{ Untreated LL patients (China)** } \\
\hline 1 & $1: 300$ & 0.01 & 0.59 & 0.46 \\
\hline 2 & & 0.00 & 0.55 & 0.50 \\
\hline 3 & & 0.06 & $>2$ & $>2$ \\
\hline 4 & & 0.02 & $>2$ & $>2$ \\
\hline 5 & & 0.14 & $>2$ & $>2$ \\
\hline 6 & & 0.00 & $>2$ & $>2$ \\
\hline 7 & & 0.00 & 0.90 & 0.82 \\
\hline 8 & & 0.02 & $>2$ & 1.74 \\
\hline 9 & & 0.03 & $>2$ & $>2$ \\
\hline 10 & & 0.01 & 0.49 & 0.36 \\
\hline \multicolumn{5}{|l|}{ Controls (China) } \\
\hline 1 & $1: 300$ & 0.00 & 0.04 & 0.02 \\
\hline 2 & & 0.01 & 0.01 & 0.01 \\
\hline 3 & & 0.01 & 0.04 & 0.04 \\
\hline 4 & & 0.01 & 0.45 & 0.41 \\
\hline 5 & & 0.01 & 0.02 & 0.02 \\
\hline 6 & & 0.01 & 0.01 & 0.00 \\
\hline 7 & & 0.02 & 0.01 & 0.01 \\
\hline
\end{tabular}

* Kindly provided by Dr U. Sengupta, Jalma Leprosy Institute, Agra, India.

** Kindly provided by Dr Li Huan-Ying, Beijing Tropical Medicine Research Institute, China.

\section{REFERENCE SERUM FOR THE DETECTION OF IGM ANTIBODIES AGAINST PG-I USING D-BSA SYNTHETIC ANTIGEN}

In the near future, in an attempt to standardize the D-BSA ELISA technique, the IMMLEP component of the UNDP/World Bank/W.H.O. Program on Tropical Disease Research will make available to interested investigators, freeze-dried samples of a D-BSA reference antigen, as well as positive and negative serum controls. The results obtained with these refer- 
Table 2. Comparison of two independent sources of D-BSA synthetic antigen as ELISA substrate for the detection of anti-PG-1 antibodies.

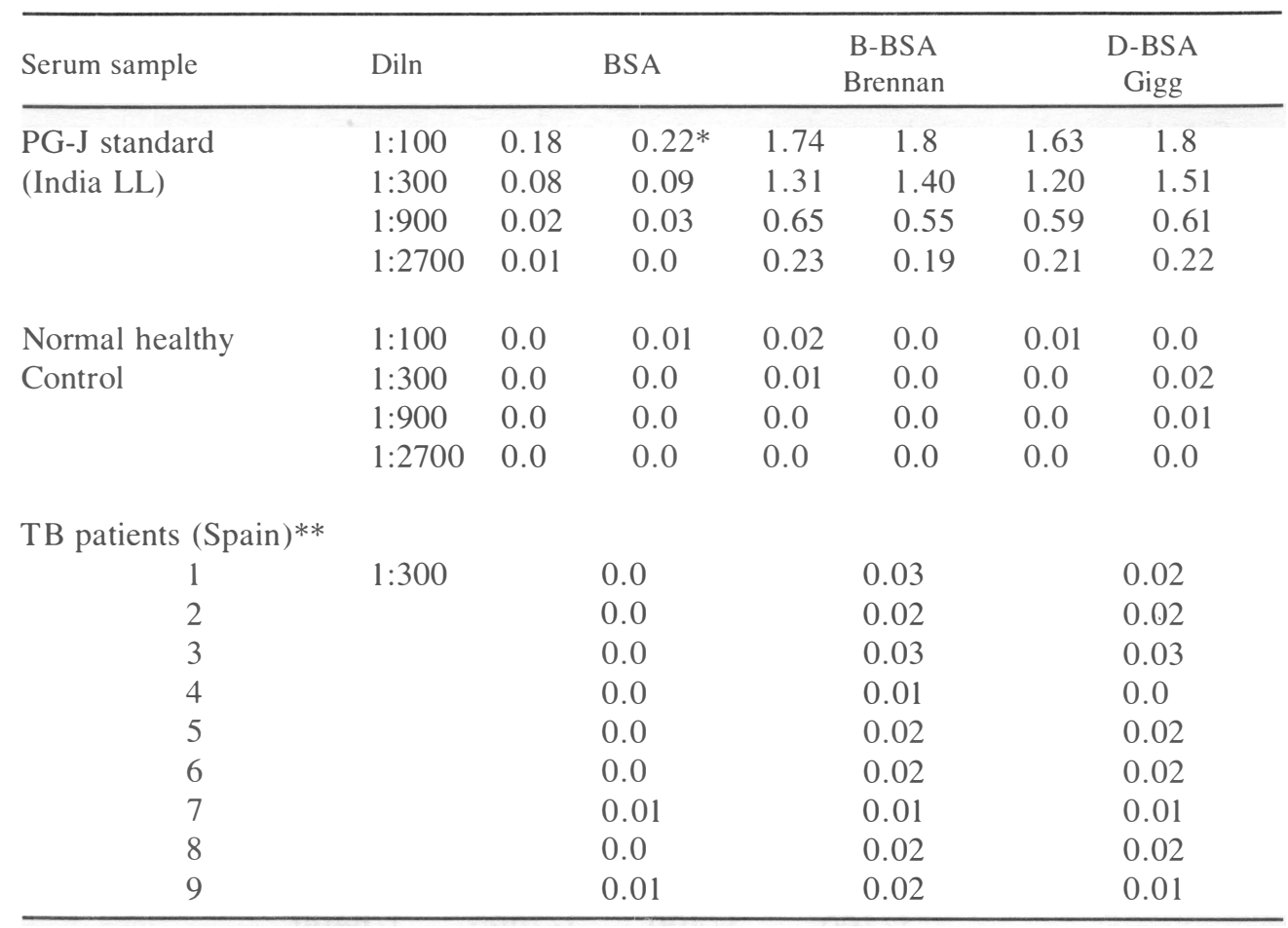

* The results for 2 separate experiments are given.

** Kindly provided by Dr R. Agüero, Santander, Spain.

ence preparations are given in figure 2. As observed above, (Tables 1 and 2) the results obtained with the proposed IMMLEP reference D-BSA and that provided by Dr P. Brennan were identical. In this way, each laboratory wishing to set up the D-BSA assay may use the D-BSA as substrate and the reference sera to establish and calibrate their own local positive and negative reference sera.

\section{SIMPLIFICATION AND STANDARDIZATION}

\section{OF SERUM SAMPLE COLLECTION TECHNIQUES}

The rapid, simple, socially acceptable collection of serum samples from individuals living in endemic areas often poses a problem for the clinical investigator. In addition, the storage and transportation of serum samples are not always easy in the field. For this reason, we have carried out preliminary experiments to compare frozen serum samples obtained by venupuncture versus whole blood finger prick samples dried on filter papers as a source of material for testing by the D-BSA ELISA. The test results, conducted blind with 60 coded, paired serum and whole blood filter paper samples are given in figure 3 and table 3 . When the results obtained testing frozen serum samples versus whole blood eluted from a «confetti» disc in 0.5 ml PBST are plotted relative to each other (figure 3), a direct correlation was observed, with 
a slight skewing in favor of the filter paper eluates. This became more evident when the results were expressed a function of the number of individuals positive in ELISA relative to the sample source (Table 3). It would appear that the results using dried whole blood samples eluted from filter paper discs in fact provided higher predictive values for leprosy patients than did the results obtained using frozen serum samples. Further studies are required to confirm these promising observations.

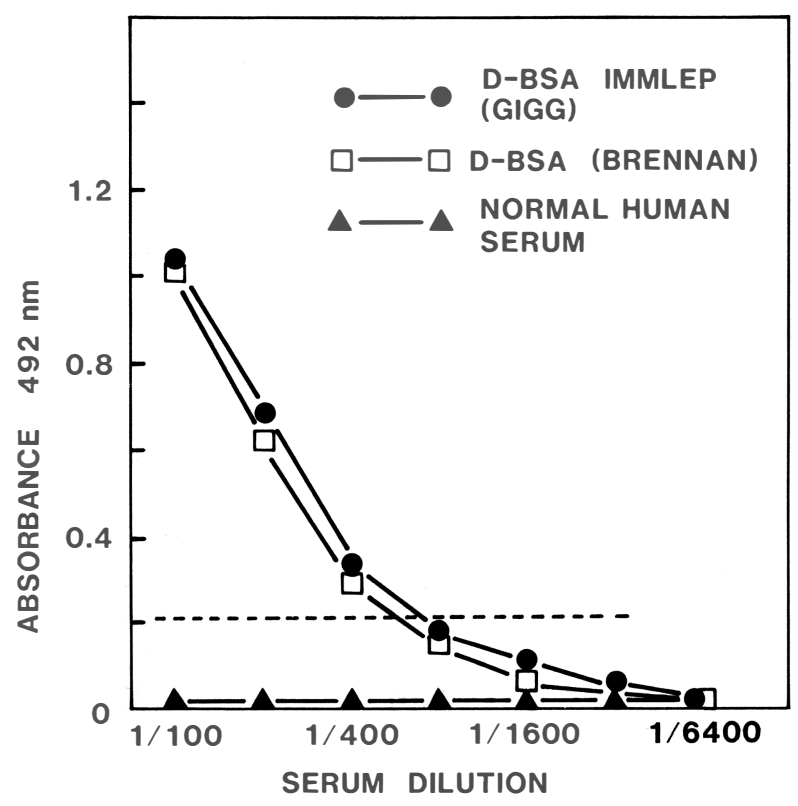

Figure 2. Proposed reference serum and D-BSA synthetic antigen for the detection of IgM

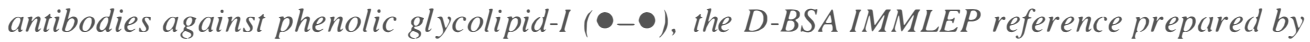
Dr R. Gigg ; $\square-\square), D$-BSA prepared by Dr P. Brennan ; $(\mathbf{\Delta}-\mathbf{\Delta})$, normal human serum tested on either of the D-BSA antigens. The reference serum consists of a strongly positive $L L$ serum (provided by $\operatorname{Dr} R$. Kaldany, AHRI/ALERT, Addis Ababa, Ethiopia), diluted 1:15 in the normal human reference serum.

Table 3. Comparison of D-BSA microplate ELISA results using frozen serum samples versus dried, whole blood samples eluted from filter papers.

\begin{tabular}{|c|c|c|}
\hline $\begin{array}{l}\text { Sample } \\
\text { source* }\end{array}$ & $\begin{array}{l}\text { Number } \\
\text { Serum } \\
(1: 300)\end{array}$ & $\begin{array}{l}\text { in ELISA } \\
\text { Filter paper } \\
\quad(\sim 1: 50)\end{array}$ \\
\hline Normal controls & $1 / 15$ & $1 / 15$ \\
\hline Multibacillary ( $\mathrm{LL}+\mathrm{BL})$ & $11 / 19$ & $16 / 19$ \\
\hline Paucibacillary $(\mathrm{BT}+\mathrm{TT})$ & $5 / 18$ & $10 / 18$ \\
\hline Contacts & $2 / 6$ & $4 / 6$ \\
\hline
\end{tabular}

* Paired serum and dried whole blood filter paper samples were provided by Dr M. Christian, Schieffelin Leprosy Treatment Center, South India. 


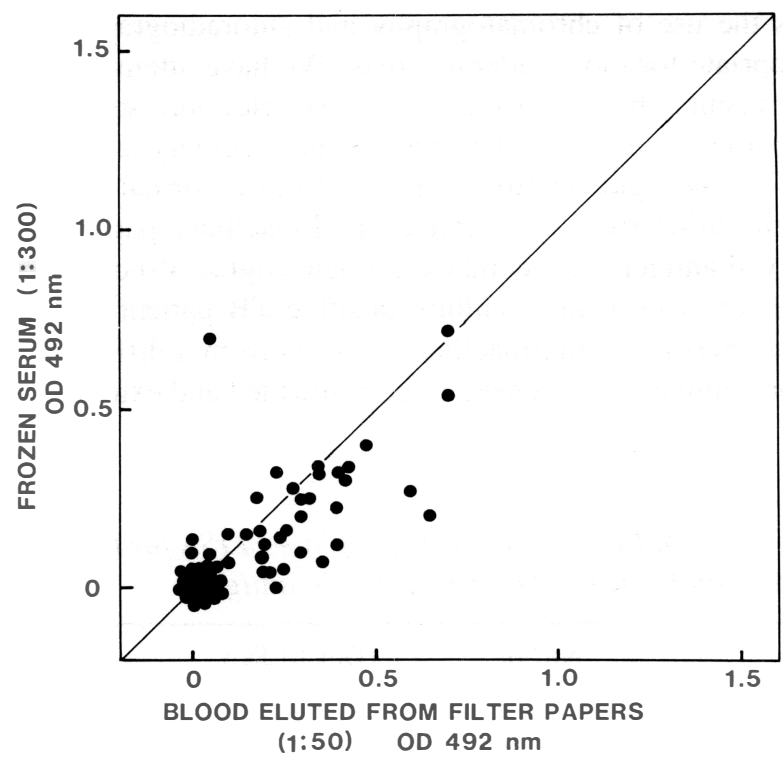

Figure 3. The comparison of frozen serum versus dried whole blood eluted from filter discs for the detection of antibodies against PG-1 using D-BSA synthetic antigen as ELISA substrate.

\section{COMPARISON OF «DOT ELISA»}

\section{VERSUS MICROPLATE ELISA USING THE D-BSA SYNTHETIC ANTIGEN}

The use of D-BSA as a substrate and nitrocellulose filters as a solid support avoids many of the problems related to the apolarity of the native PG-I molecule (e.g. hexane as solvent, polysulfone filter paper supports, etc). The use of an incubation chamber allows one to test 96 samples at once, a considerable saving of time and effort over previously described «dipstick» methods (15). In addition, the D-BSA is spotted in $1 \mu \mathrm{l}$ in the center of the sample well, enabling one to distinguish between a true positive (O) and a false positive due to non-specific sticking $(\bullet)$. Of course, a false positive may mask a true positive reaction, and then titration studies are required.

In order to evaluate the «dot ELISA» technique, 239 sera were assayed blind at a dilution of 1:300 both by «dot ELISA» and the conventional microplate ELISA. The study included 104 normal sera, 60 culture positive tuberculosis sera and 69 leprosy sera (Table 4). It is evident from the results that the two forms of ELISA gave virtually identical results, both in terms of \% positivity (Table 4 ) and in terms of sensitivity and specificity (Table 5).

The reproducibility of the dot ELISA was quite acceptable. A titration of four multibacillary sera was carried out on seven different occasions, giving an average coefficient of variation of 7.7 and therefore a reproducibility of $92.3 \%$. None of the three normal sera examined gave a positive result when tested a total of seven times.

\section{DETECTION OF PG-I ANTIGEN IN URINE SAMPLES USING «DOT ELISA»}

Since antigen detection represents the ultimate measure of parasitic infection, the development of rapid, simple diagnostic tests for the measurement of $M$. leprae-specific antigen(s) would be a major achievement. The recently reported assay for the detection of PG-I in body 
fluids (13) requires the use of chromatography and autoradiographic techniques, methods which are not appropriate for most endemic areas. We have attempted to modify this assay, and the preliminary results obtained using a rapid, simple, non-isotopic «dot ELISA» method for the detection of PG-I antigen in the urine of multibacillary leprosy patients are given in figure 4. In figure $4 a$, the lipid fraction extracted from a normal urine sample (India) was negative, whereas the urine from an untreated multibacillary patient (Spain) diagnosed in Geneva contained PG-I antigen. A second experiment (figure 4b) confirmed these results i.e. normal urine (India) or urine from a culture positive TB patient (Vietnam) was negative, whereas the urine samples from multibacillary patients from 4 different countries were positive. Again, these preliminary results need to be confirmed and extended to pilot field studies in endemic areas.

Table 4. Comparison of "dot ELISA» versus microplate ELISA for the detection of antibodies against phenolic glycolipid 1 using D-BSA synthetic antigen.

\begin{tabular}{lccccc}
\hline $\begin{array}{l}\text { Serum } \\
\text { classification }\end{array}$ & $\begin{array}{c}\text { No. of } \\
\text { cases }\end{array}$ & \multicolumn{2}{c}{ Positive } & $(\%)$ & \multicolumn{2}{c}{ Microplate ELISA } \\
Positive & $(\%)$ \\
\hline Multibacillary & 43 & 31 & $(72)$ & 32 & $(74)$ \\
Paucibacillary & 26 & 10 & $(38)$ & 10 & $(38)$ \\
Tuberculosis & 60 & 5 & $(8)$ & 7 & $(12)$ \\
Normal & 104 & 9 & $(9)$ & 7 & $(8)$ \\
Contacts & 6 & 2 & $(33)$ & 2 & $(33)$ \\
\hline
\end{tabular}

Table 5. Sensitivity and specificity of dot ELISA versus microplate ELISA.

\begin{tabular}{ccc}
\hline & Dot ELISA (\%) & Microplate ELISA (\%) \\
\hline Sensitivity & 72 & 74 \\
multibacillary sera & 38 & 38 \\
paucibacillary sera & & \\
Specificity & 91 & 92 \\
normal sera & 91 & \\
\hline
\end{tabular}

\section{Discussion}

The results presented above illustrate various attempts to simplify and standardize existing techniques for the detection of $M$. leprae-specific antibodies and antigens. The availability of reference samples of D-BSA synthetic antigen and positive and negative control sera should contribute considerably to the standardization of assays and interpretation of results from various laboratories, since the ELISA assay itself is extremely reproducible. The potential use of finger prick blood sample collection for the PG-I antibody assay appears promising. Hopefully, the sensitivity of the PG-I antigen detection assay can be improved (perhaps using PG-I specific Mabs), so that the same filter paper sample could be tested for both antibody and antigen activity. The results presented for the simple, rapid, specific detection of PG-I antigen in the urine of multibacillary patients is also encouraging. The next step will be to eliminate the lipid extraction step; e.g. by passing the urine over a filter paper already spotted 

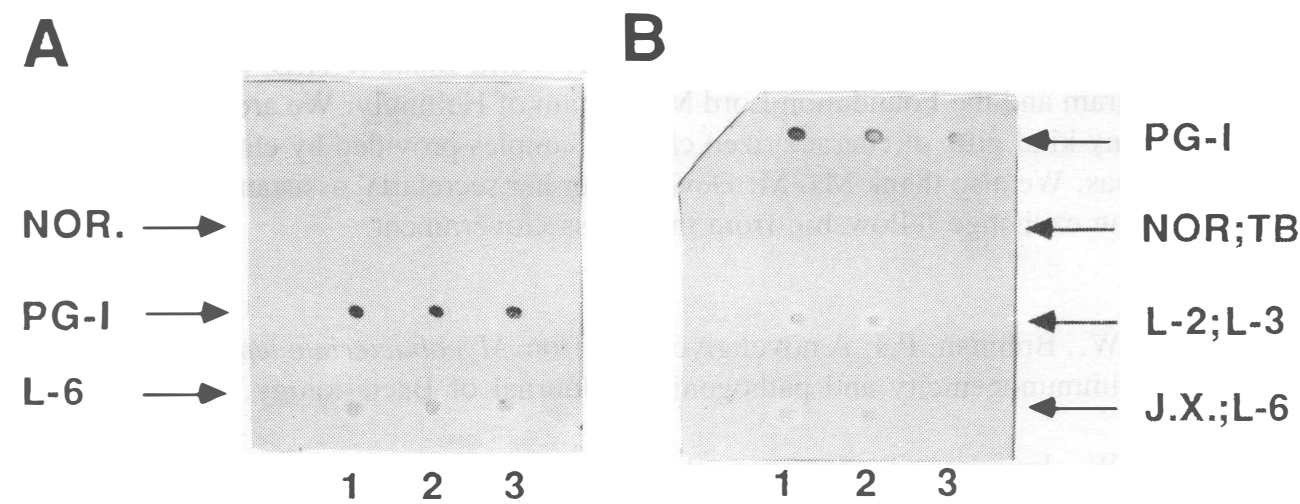

Figure 4. Detection of PG-I antigens in urine samples from leprosy patients using a simple, rapid "dot ELISA» technique. The PG-I spots in 1, 2 and 3 represent 100 ng, 33 ng and $10 \mathrm{ng}$ of authentic PG-I. In figure A, NOR and L-6 represent lipids extracted from normal urine (India) and urine from an untreated multibacillary patient (Spain) respectively. In figure $B, T B$ refers to a urine sample from a culture positive tuberculosis patient (Vietnam); L-2 and $L-3$ are $2 B L$ cases under treatment for 1 year (Egypt and Cambodia). J.X. represents an untreated LL patient (Brazil). In all cases, $1 \mu$ l of lipid extract in hexane was spotted, corresponding to $0.4 \mathrm{ml}$ of native urine, the lower level of detection in this assay.

with anti-PG-I antibodies. And finally, the «dot ELISA» assay for anti-PG-I antibody detection using the D-BSA substrate and nitrocellulose membranes as a solid phase represents a rapid, simple, direct visual means of identifying antibody positive individuals in endemic areas. The suitability of these tests for routine use in endemic regions will have to be confirmed by pilot field studies.

As a direct result of the production of $M$. leprae specific Mabs (18), several laboratories have reported the identification and characterization of $M$. leprae-specific antigens $(19,20)$, in addition to the PG-I described in this paper. It is to be hoped that eventually a battery of antigens and antibodies will become available which will allow the identification of all leprosy patients, not only those at the multibacillary end of the spectrum. The recent report by Klatser et al. (20) concerning the use of a $36 \mathrm{kd} M$. leprae antigen for the serodiagnosis of leprosy certainly appears promising. The use of defined synthetic peptide epitopes for assessing the cellular immune status of leprosy patients $(21,22)$ also should provide a new approach to the problems of diagnosis and monitoring the immune status of the participants of future vaccination trials. In this context, a defined synthetic skin test antigen preparation should soon be available.

In spite of the recent technological advances which have led to the production of $M$. leprae-specific Mabs, together with defined synthetic and recombinant antigens, the application of these tools to the improved control of leprosy remains to be defined. The detection of early leprosy when clinical signs are equivocal, the detection of early relapse and the monitoring of patients for progress under chemotherapy relate to selected groups, and therefore the use of a simple, reliable test could be cost efficient. However, it must be emphasized that while sero-diagnostic tests should be of great value in understanding better the epidemiology of leprosy, a direct application of such tests in leprosy control operations is not likely to be highly beneficial or logistically feasible. 


\section{Acknowledgements}

This work was supported by grants from the UNDP/World Bank/W.H.O Tropical Disease Research Program and the Foundation Lord Michelham of Hellingly. We are most appreciative of the many kind gifts of characterized clinical samples provided by clinicians working in endemic areas. We also thank Ms. M. Devouge for her secretarial assistance. G.A.S. was supported by an exchange fellowship from the Swiss Government.

\section{References}

1 Hunter, S.W., Brennan, P.J. A novel glycolipid from Mycobacterium leprae possibly involved in immunogenicity and pathogenicity. Journal of Bacteriology, 1981; 147 (3): 728.

2 Hunter, S.W., Fujiwara, T., Brennan, P.J. Structure and antigenicity of the major specific glycolipid antigen of Mycobacterium leprae. J. Biol. Chem., 1982; 257: 15072.

3 Brennan, P.J. New found glycolipid antigens of mycobacteria. Microbiology, 1984; 366.

4 Cho, S-N., Yanagihara, D.L., Hunter, S.W., Gelber, R.H., Brennan, P.J. Serological specificity of phenolic glycolipid-I from Mycobacterium leprae and use for serodiagnosis of leprosy. Infect. Immun., 1983; 41: 1077.

5 Brett, S.J., Draper, P., Payne, S.N., Rees, R.J.W. Serological activity of characteristic phenolic glycolipid from Mycobacterium leprae in sera from patients with leprosy and tuberculosis. Clin. Exp. Immunol., 1983; 52: 271.

6 Young, D.B., Buchanan, T.M. A serological test for leprosy with a glycolipid specific for Mycobacterium leprae. Science, 1983; 221: 1057.

7 Young, D.B., Khanolkar, S.R., Buchanan, T.M. Generation and characterization of monoclonal antibodies to the phenolic glycolipid of Mycobacterium leprae. Infect. Immun., 1984; 43: 183.

8 Fujiwara, T., Hunter, S.W., Cho S-N., Aspinall, G.O., Brennan, P.J. Chemical synthesis and serology of disaccharides and trisaccharides of phenolic antigens from the leprosy bacillus and preparation of a disaccharide protein conjugate for serodiagnosis of leprosy. Infect. Immun., 1984; 43: 254.

9 Cho, S-N., Fujiwara, T., Hunter, S.W. et al. Use of an artifical antigen containing the 3,6-di-O-methyl-D-glucopyranosyl epitope for the serodiagnosis of leprosy. J. Infect. Dis., 1984; 150: 311 .

10 Gigg, J., Gigg, R., Payne, S., Conant, R. The allyl group for protection in carbohydrate chemistry. 17* synthesis of propyl-0-(3,6-Di-0-methyl- $\beta$-D-glucopyranosyl)-( $1 \rightarrow$ 4)-0-(2,3-Di-0-methyl- $\alpha$-L-rhmanopyoanosyl)-1( $\rightarrow$ 2)-3-0-methyl- $\alpha$-L-rhamnopyranoside: the oligosaccharide portion of the major serologically active glycolipid from Mycobacterium leprae. Chemistry and Physics of Lipids 1985 (38): 299.

11 Brett, S.J., Payne, S.N., Gigg, J., Burgess, P., Gigg, R. Use of synthetic and immunodominant epitope of phenolic glycolipid I in the serology of leprosy. Clin. Exp. Immunol., 1986; 64: 476.

12 Young, D.B., Fohn, M.J., Buchanan, T.M., Use of a polysulfone support for immunochemical analysis of a glycolipid from Mycobacterium leprae. J. Immunol. Methods, 1985; 79: 205.

13 Young, D.B., Harnish, J.P., Knight, J., Buchanan, T.M. Detection of phenolic glycolipid I in sera from patients with lepromatous leprosy. J. Infect. Dis., 1985; 152: 1078.

14 Serological tests for leprosy. Lancet, March 8, 1986, pp. 533.

15 Young, D.B., Fohn, M.J., Khanolkar, S.R., Buchanan, T.M. A spot test for detection of antibodies to phenolic glycolipid I. Lepr. Rev., 1985; 56: 193. 
16 Bligh, E.G., Dyer, W.J. A rapid method for total lipid extraction and purification. Can. J. Biochem. Physiol., 1959; 37: 912.

17 Kumar, S., Band, A.H., Samantaray, J.C., Dang, N., Talwar, G.P. A dot enzyme linked immunosorbent assay for detection of antibodies against Entameoba histolytica. J. Immunol. Meth., 1985; 83: 125.

18 Engers, H.D., Abe, M., Bloom, B.R. et al. Results of a World Health Organizationsponsored workshop on monoclonal antibodies to Mycobacterium leprae. Infect. Immun., 1985; 48: 603 .

19 Sinha, S., Sengupta, U., Ramu, G., Ivanyi, J. A serological test for leprosy based on competitive inhibition of monoclonal antibody binding to the My2a determinant of $M y$ cobacterium leprae. Trans. R. Soc. Med. Hyg., 1983; 77: 869.

20 Klatser, P.R., De Witt, M.Y.L., Kolk, A.H.J. An ELISA-inhibition test using monoclonal antibody for the serology of leprosy. Clin. exp. Immunol., 1985; 62: 468.

21 Mustafa, A.S., Gigg, H.K., Nerland, A. et al. Human T cell clones recognize a major M. leprae protein antigen expressed in E. coli. Nature, 1986; 319: 63.

22 Ottenhoff, T.H.M., Klatser, P.R., Ivanyi, J. et al. Mycobacterium leprae-specific protein antigens defined by cloned human helper T cells. Nature, 1986; 319: 66. 